\title{
A quantitative evaluation of gross versus histologic neuroma formation in a rabbit forelimb amputation model: potential implications for the operative treatment and study of neuromas
}

\author{
Jason $\mathrm{H} \mathrm{Ko}^{1}$, Peter S Kim ${ }^{1}$ Kristina D O'Shaughnessy ${ }^{1}$, Xianzhong Ding ${ }^{2}$, Todd A Kuiken ${ }^{3}$ and \\ Gregory A Dumanian ${ }^{1,3^{*}}$
}

\begin{abstract}
Background: Surgical treatment of neuromas involves excision of neuromas proximally to the level of grossly "normal" fascicles; however, proximal changes at the axonal level may have both functional and therapeutic implications with regard to amputated nerves. In order to better understand the retrograde "zone of injury" that occurs after nerve transection, we investigated the gross and histologic changes in transected nerves using a rabbit forelimb amputation model.
\end{abstract}

Methods: Four New Zealand White rabbits underwent a forelimb amputation with transection and preservation of the median, radial, and ulnar nerves. After 8 weeks, serial sections of the amputated nerves were then obtained in a distal-to-proximal direction toward the brachial plexus. Quantitative histomorphometric analysis was performed on all nerve specimens.

Results: All nerves demonstrated statistically significant increases in nerve cross-sectional area between treatment and control limbs at the distal nerve end, but these differences were not observed $10 \mathrm{~mm}$ more proximal to the neuroma bulb. At the axonal level, an increased number of myelinated fibers were seen at the distal end of all amputated nerves. The number of myelinated fibers progressively decreased in proximal sections, normalizing at 15 $\mathrm{mm}$ proximally, or the level of the brachial plexus. The cross-sectional area of myelinated fibers was significantly decreased in all sections of the treatment nerves, indicating that atrophic axonal changes proceed proximally at least to the level of the brachial plexus.

Conclusions: Morphologic changes at the axonal level extend beyond the region of gross neuroma formation in a distal-to-proximal fashion after nerve transection. This discrepancy between gross and histologic neuromas signifies the need for improved standardization among neuroma models, while also providing a fresh perspective on how we should view neuromas during peripheral nerve surgery.

Keywords: Neuroma, targeted reinnervation, axon reaction, histomorphometry, brachial plexus

\section{Background}

When a peripheral nerve is transected, the distal nerve segment undergoes Wallerian degeneration and, without coaptation to proximal nerve tissue, eventually disappears [1]. The proximal nerve stump, in contradistinction, has

\footnotetext{
*Correspondence: gdumania@nmh.org

'Department of Surgery, Division of Plastic and Reconstructive Surgery, Northwestern University, Feinberg School of Medicine, Chicago, IL, USA Full list of author information is available at the end of the article
}

the ability to regenerate and send axon sprouts into the distal nerve segment, potentially proceeding to the target organs $[2,3]$. However, when regenerating axons fail to reach the distal segment, a neuroma forms, and axons cease to grow [4]. On a microscopic level, these neuromas consist of disorganized, chaotic myelinated axons encased in significant connective tissue stroma [5], and they are frequently sensitive to pressure, causing a classic focal neuroma pain $[6,7]$. Neuroma pain can be both 
physically and psychologically disabling and is often difficult to treat $[8,9]$. Numerous surgical techniques have been proposed for the prevention and treatment of neuromas, including simple ligation $[10,11]$; capping the nerve stump with various materials [12-15]; translocation into nerve tissue through end-to-side or centro-central coaptation [16-18]; and transposition of the nerve ending into bone [8,19], fat $[20,21]$, muscle [6,22-24], and, more recently, vein [25-28]. As implied by the large number of techniques to prevent and treat neuromas, there is no consensus yet on which method is most effective. Regardless of technique, however, the fundamental principle of neuroma surgery involves excising the injured nerve segment proximally to the level of grossly normal fascicles. Yet the zone of injury of a peripheral nerve ending in a classic neuroma is not defined, and understanding the microanatomy of these situations is important both in clinical peripheral nerve surgery, as well as for the standardization of all animal nerve models that attempt to investigate neuroma treatments.

Targeted reinnervation is a revolutionary strategy performed in upper extremity amputees where the stumps of amputated nerves of the brachial plexus are transferred to denervated, otherwise functionless, remnant muscles in the shoulder, chest, and/or proximal arm, in order to achieve a functioning neural-machine interface that allows amputees to voluntarily control motorized prostheses just as they would control their native limbs [29-34]. In order to further investigate targeted reinnervation at a level just distal to the brachial plexus, we developed a novel rabbit forelimb amputation model that is a well-tolerated and reproducible quantitative model of end-neuroma formation [35]. An amputation model was created to better simulate the clinical scenario of limb amputation, as well as to increase the number of neuromas created per animal (and thereby decrease the total number of animals sacrificed), and the amputation was performed in the proximal forelimb in order to mimic the clinical scenario that is often encountered in targeted reinnervation. Although previous studies have examined the retrograde axonal changes that occur after nerve transaction [36-42], there is sparse data regarding the distal-to-proximal histologic changes that occur in the proximal nerve stump, as they relate to gross nerve appearance, after amputation injury at the brachial plexus level.

\section{Materials and methods}

This study was approved by the Northwestern University Institutional Animal Care and Use Committee (IACUC) prior to its initiation. Four 6-month old (2.5$3.5 \mathrm{~kg}$ ) female New Zealand White rabbits (Covance Inc., Princeton, NJ) were acquired and single-housed with food and water ad libitum.

\section{Operative Technique}

The pre- and post-operative care of the animals were outlined in detail in a previous study, as was the surgical technique [35]. Briefly, under sterile conditions, an elliptical incision was made around the left proximal forelimb, and the distal skin overlying the forelimb was elevated in a circumferential, de-gloving fashion. The nervous structures-with special attention directed to the median, radial, and ulnar nerves-were exposed and identified as they exited the brachial plexus, and the median, radial, and ulnar nerves were each transected 2 $\mathrm{cm}$ distal to where they branched off of the brachial plexus and loosely sutured to the anterolateral aspect of the normally innervated pectoralis superficialis transversus muscle using 7-0 polypropylene suture (Prolene suture, Ethicon Inc., Somerville, NJ) (Figure 1). All muscles and tendons were disinserted from the humerus, and a shoulder disarticulation amputation was performed. The remaining muscles were sutured together over the glenoid fossa and any remaining bony prominences using 4-0 polyglactin (Vicryl suture, Ethicon), and the skin incision was closed in a running subcuticular fashion using 4-0 polyglactin suture. Following recovery, the rabbits were inspected daily for abnormal activity, evidence of pain, and post-operative wound complications.

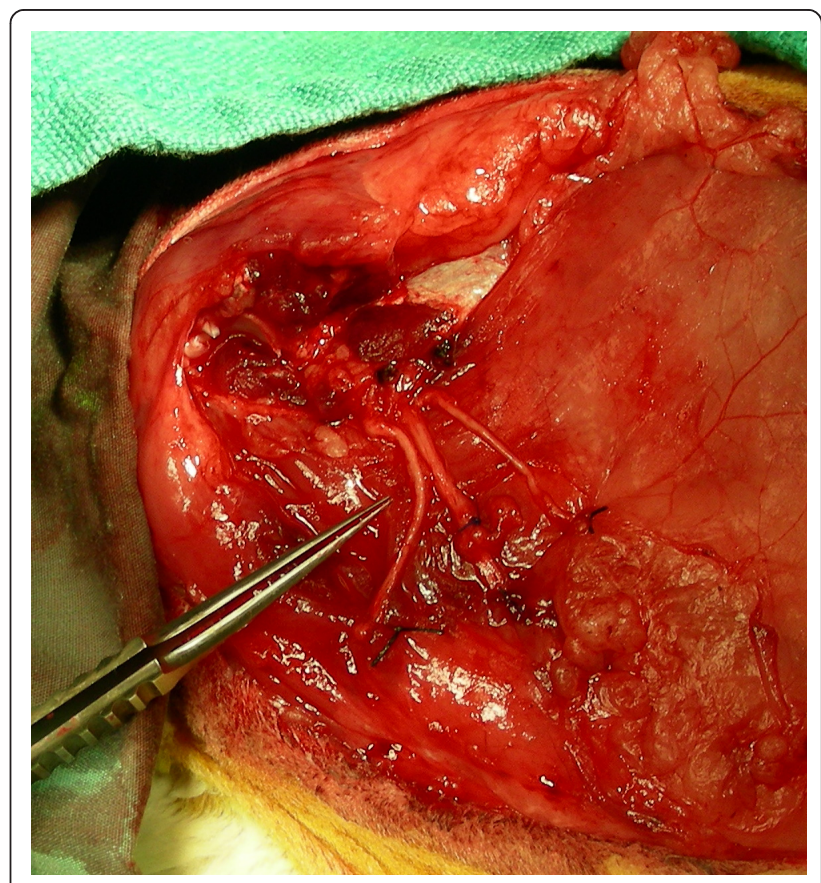

Figure 1 The amputated stumps of the median (left), radial (center), and ulnar (right) nerves are loosely sutured to the pectoralis superficialis transversus using 7-0 polypropylene suture to ease identification and location of the neuromas at the time of harvest. 


\section{Tissue Harvest and Preparation}

Eight weeks post-amputation, the rabbits were euthanized, and the original surgical incision was re-opened, with the median, radial, and ulnar neuromas dissected out and brought to length. After excising the distal 5 $\mathrm{mm}$ of neuroma/nerve, which is typically performed in targeted reinnervation procedures, in addition to other nerve transfer and neuroma procedures, 7-0 polypropylene sutures were used to mark the remaining distal segment of each nerve, in addition to $5 \mathrm{~mm}$ proximally, 10 $\mathrm{mm}$ proximally, and $15 \mathrm{~mm}$ proximally toward their branch points off the brachial plexus (Figure 2). Serial nerve sections were harvested at each location as indicated by the suture markings. In the contralateral limb, serial nerve sections were obtained from the median, radial, and ulnar nerves at corresponding lengths-distal end, $5 \mathrm{~mm}$ proximally, $10 \mathrm{~mm}$ proximally, and $15 \mathrm{~mm}$ proximally-relative to their branch points off the brachial plexus to serve as controls. In all animals, after excising the distal $5 \mathrm{~mm}$ of nerve tissue, $20 \mathrm{~mm}$ proximally represented the level of the brachial plexus.

Harvested nerve specimens ( $n=96$ total) were fixed in $4 \%$ EM grade glutaraldehyde (Polysciences Inc., Warrington, PA) at $4^{\circ} \mathrm{C}$, post-fixed with $2 \%$ osmium tetroxide (Polysciences) and serially dehydrated in ethanol. Specimens were embedded in Poly/Bed ${ }^{\circledR} 812$ BDMA (Polysciences) and cut into $1-\mu \mathrm{m}$ cross-sections with a Leica Ultracut UCT ultramicrotome (Leica

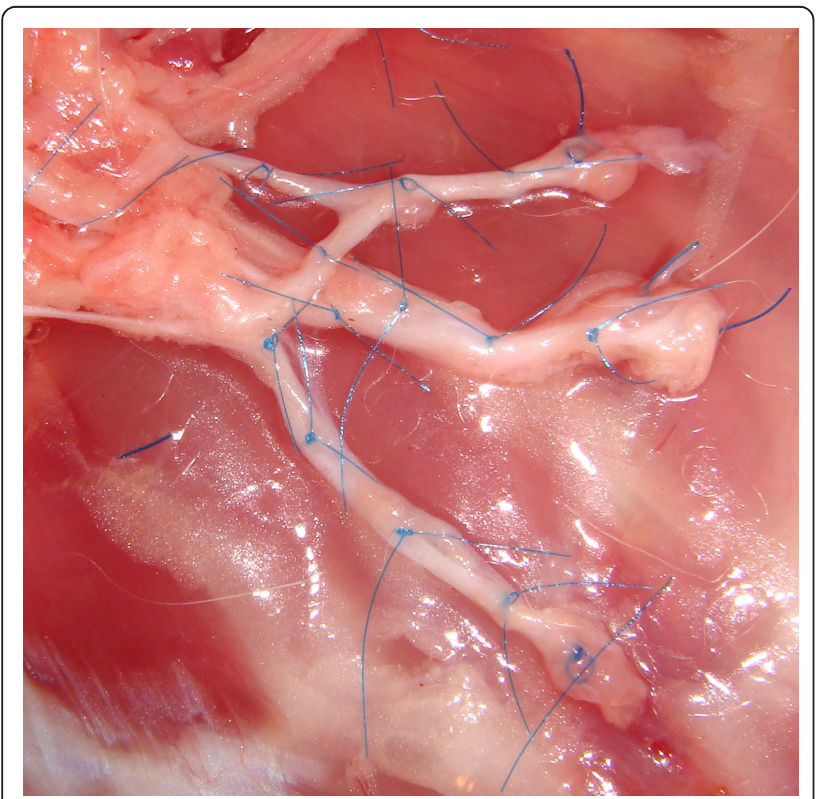

Figure 2 Six to 8 weeks post-amputation, after the distal $5 \mathrm{~mm}$ of the median (top), radial (center), and ulnar (bottom) neuromas was excised, 7-0 polypropylene sutures were placed at the distal segment, and at 5, 10, and $15 \mathrm{~mm}$ proximally toward their branch points off the brachial plexus.
Microsystems Ltd., Wetzlar, Germany). Sections were then stained with $1 \%$ toluidine blue, and mounted and cover-slipped for imaging.

\section{Histomorphometric Analysis}

A Nikon DS-5M-U1 (Nikon Instruments Inc., Melville, NY) digitizing camera was mounted onto a Nikon Eclipse 50i (Nikon) microscope with a manually controlled stage. Nikon NIS-Elements BR 2.3 (Nikon) imaging software was used to perform nerve histomorphometric analysis of all slides. Using a semiautomated technique, characterized by dynamic thresholding and manual fiber elimination, [43,44] each nerve was analyzed to determine the nerve cross-sectional area, the myelinated axon count in each nerve cross-section, and the cross-sectional areas of the axons including their myelin sheaths. In order to prevent grading bias, prepared slides from amputated and control sides were randomly assigned numbers for analysis with their identification marks covered.

\section{Statistical Analysis}

Control nerve sections at each location (distal end, 5 $\mathrm{mm}$ proximally, $10 \mathrm{~mm}$ proximally, and $15 \mathrm{~mm}$ proximally) were grouped according to nerve (median, radial, and ulnar nerves), and an analysis of variance (ANOVA) with Bonferroni post-test analysis was performed for each of the three following histomorphometric parameters: 1) nerve cross-sectional area; 2) myelinated axon count; and 3) myelinated axon cross-sectional area. There were no significant differences amongst nerve type for each variable, so the treatment nerves for the median, radial, and ulnar nerves at each location were compared to grouped control nerves for each nerve type using the two-tailed Student's $t$-test to analyze nerve cross-sectional area, myelinated axon count, and myelinated cross-sectional area. A $p$-value $<0.05$ was considered statistically significant.

\section{Results}

Gross examination of the amputated nerve stumps revealed traumatic neuroma tissue that was enlarged with nodular fusiform formation at the distal end of each of the transected nerves. Fibrosis was also present, resulting in adhesions to the surrounding tissue. The aforementioned macroscopic findings, especially the nerve calibers, normalized by $5 \mathrm{~mm}$ proximally in all of the transected nerves, and sectioning of the nerves demonstrated grossly normal fascicles $5 \mathrm{~mm}$ proximal to the distal end. Microscopically, the nerve architecture at the amputation site was disorganized with extensive nerve fiber regeneration and disorientation. Uneven distribution of regenerative nerve fibers was observed with variation of axonal bundle density from area to area, 
and marked variation in shape and size of axonal bundles was also observed. Dramatic fibrosis was seen between the regenerative nerve bundles (Figure 3). Under higher microscopic magnification, interstitial stroma between regenerative axonal bundles was fibrotic with collagen deposition. Smaller, disorganized myelinated fibers, with qualitatively increased amounts of myelin infolding, crenation, and debris were seen at the distal end of each proximal nerve stump. In the amputated nerve stumps, axonal regeneration, axonal bundle disorganization and disorientation, and interstitial fibrosis progressively normalized in a distal-to-proximal fashion but are still present even at a distance of $15 \mathrm{~mm}$ proximal to the distal neuroma end when compared to control nerve specimens. The aforementioned qualitative observations were confirmed by histomorphometric analysis.

\section{Nerve Cross-Sectional Area}

As Figure 4 demonstrates, the mean cross-sectional area of the median nerve at the distal end for the amputation group had a 1.7-fold increase compared to that for the control group ( $p=0.001)$, and the median nerve segments at $5 \mathrm{~mm}$ were 1.4 times larger than corresponding controls $(\mathrm{p}=0.04)$. Of note, the median nerve sample $15 \mathrm{~mm}$ proximally demonstrated a $33 \%$ decrease in mean cross-sectional area for the amputation group compared to the control group $(\mathrm{p}=0.03)$. For the radial nerve, the mean cross-sectional area at the distal end was 3.2 times greater in the amputation group than in the control group ( $\mathrm{p}<0.0001$ ), and at $5 \mathrm{~mm}$ proximally, the cross-sectional area for the amputated radial nerve was significantly greater (by a factor of 1.7) compared to control ( $\mathrm{p}<0.0001)$. The amputation group demonstrated a 2.5-fold increase in cross-sectional area of the ulnar nerve at the distal end compared to control ( $\mathrm{p}<$ $0.0001)$. Once again, the amputated group had a larger mean cross-sectional area at $5 \mathrm{~mm}$ proximally, but this was not statistically different than the control group.

\section{Myelinated Axon Count}

As demonstrated in Figure 5, the myelinated axon count at the distal end of the median nerve demonstrated a 2.4-fold increase in the amputation group when compared to the control group $(\mathrm{p}<0.0001)$. Five $\mathrm{mm}$ proximally, the axon counts were 1.9 times higher in the amputated nerves $(\mathrm{p}=0.0003)$, and $10 \mathrm{~mm}$ proximally, the axon counts were 1.4 times higher in the amputated nerves $(p=0.004)$. The mean myelinated axon count for the radial nerve was 2.4 times higher at the distal end in the amputation group ( $\mathrm{p}<0.0001) ; 1.7$ times higher 5 $\mathrm{mm}$ proximally in the amputation group ( $\mathrm{p}<0.0001)$; and 1.4 times higher $10 \mathrm{~mm}$ proximally in the amputation group $(\mathrm{p}=0.001)$. The ulnar nerve demonstrated the same trend with an increased myelinated axon count by a factor of 2.8 for the amputation group at the



Figure 3 (Above) Median nerve. (Center) Radial nerve. (Below) Ulnar nerve with toluidine blue staining at 400x magnification. (First column) Smaller, disorganized myelinated fibers, with qualitatively increased amounts of myelin infolding, crenation, and debris are seen at the distal end of each proximal nerve stump. Regenerative clusters with axon sprouting are more prevalent at the distal ends, as is the amount of connective tissue stroma. (Second, third, and fourth columns) The myelinated fibers become progressively more organized and larger at 5, 10, and 15 mm proximally, although myelin debris and crenation are still noted. (Fifth column) The control nerves demonstrate organized, circular, and larger fibers with no noticeable myelin debris. 


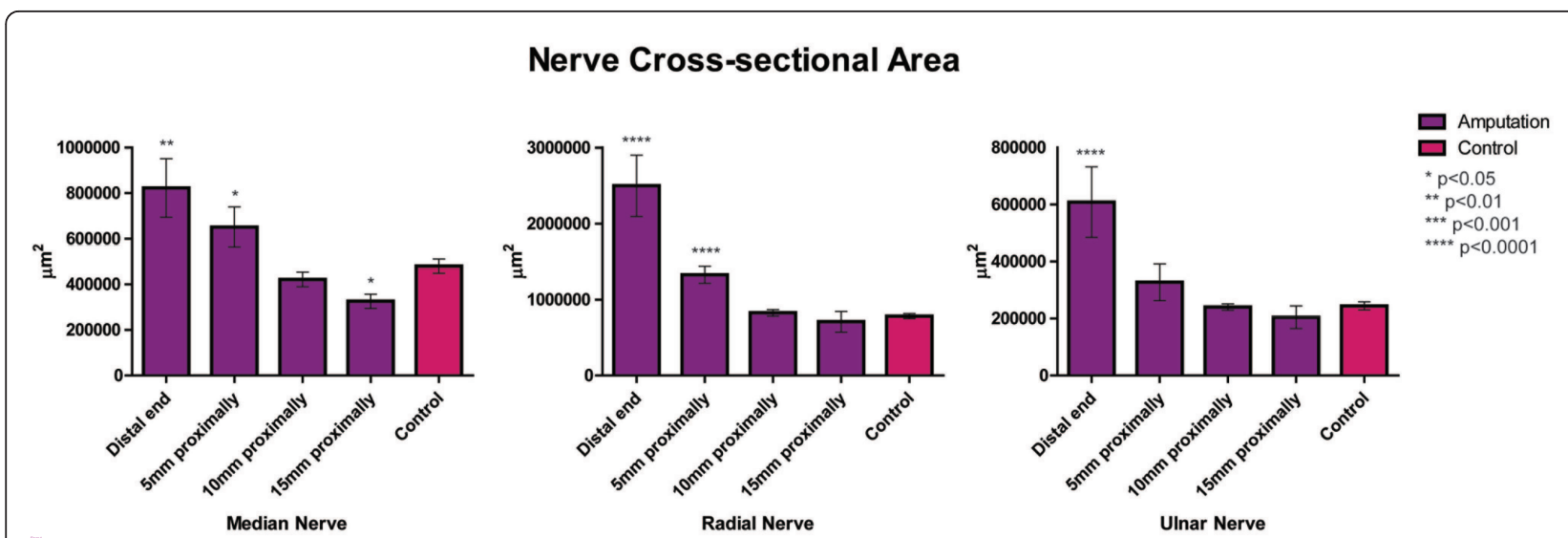

Figure 4 The nerve cross-sectional area of the median, radial, and ulnar nerves compared to control nerves at the time of harvest (68 weeks).

distal end ( $p<0.0001)$ and a 1.8 -fold increase in the amputation group $5 \mathrm{~mm}$ proximally $(\mathrm{p}=0.005)$. There was no significant difference in the axon counts for any amputated nerve groups $15 \mathrm{~mm}$ proximally compared to the normal control group.

\section{Myelinated Axon Cross-Sectional Area}

Figure 6 shows significant decreases in mean myelinated axon cross-sectional area for the median, radial, and ulnar nerves in amputation versus control groups at all nerve distances ( $\mathrm{p}<0.0001$ for distal end, 5, 10, and 15 $\mathrm{mm}$ proximally). The average cross-sectional areas were smallest near the neuroma, and axon cross-sectional areas increased progressively as the nerve was sectioned more proximally. However, the myelinated axon area did not normalize to the control group values. This pattern was also consistently demonstrated in the radial nerve ( $\mathrm{p}<0.0001$ for distal end, 5,10 , and $15 \mathrm{~mm}$ proximally) and in the ulnar nerve ( $\mathrm{p}<0.0001$ for distal end, 5, 10, and $15 \mathrm{~mm}$ group).

\section{Discussion}

Inspired by findings both in the laboratory and in the operating room, this study was undertaken to better understand the microanatomic changes that occur to the proximal end of a chronically transected peripheral nerve. First described by Waller in 1850 [1], the changes that occur in the distal segment of a transected nerve are accordingly referred to as Wallerian degeneration; however, in addition to changes in the distal nerve segment, Waller also described the generation of neural tissue from the proximal nerve, which was further described and pioneered by Ramón y Cajal [2].

In the proximal nerve segment, a series of histologic changes occur in a process referred to as the axon reaction, retrograde effect, and/or traumatic degeneration,

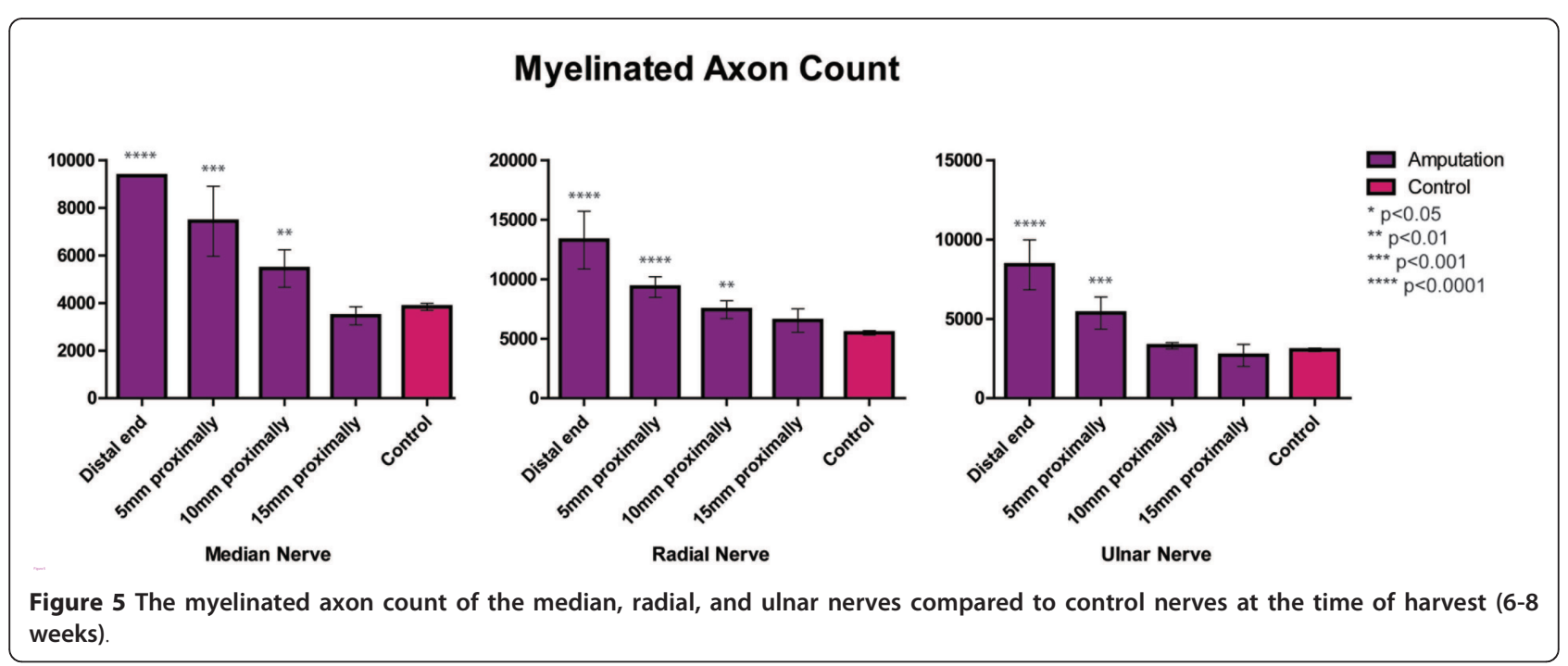




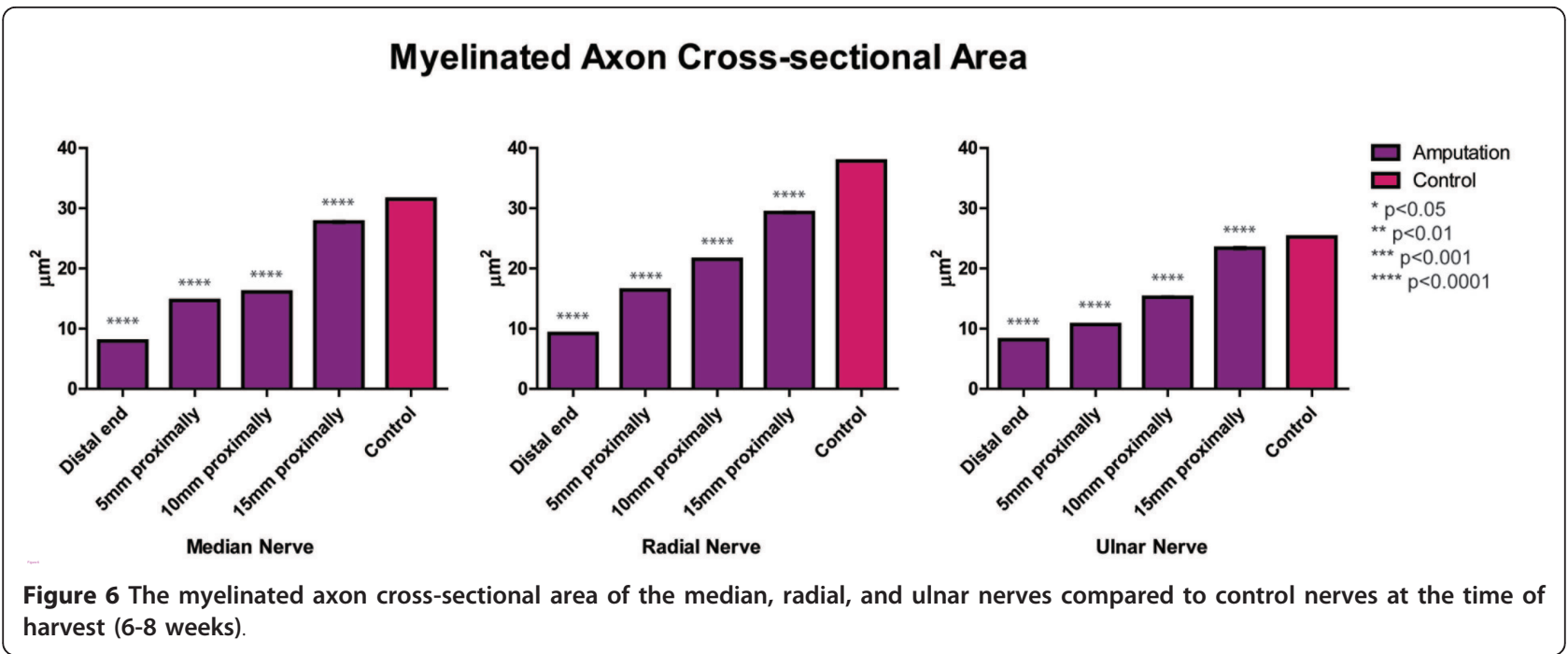

amongst other names [45-47]. During the axon reaction, according to Sunderland, anywhere from 17 to $94 \%$ of nerve fibers die [48], mostly as a result of diminished target-derived neurotrophic support $[49,50]$. In several studies on the axon reaction in a cat hindlimb amputation model, Dyck et al. described the series of cellular events after permanent axotomy as they progress from axonal atrophy to demyelination and, ultimately, axonal degeneration $[37,38,51]$. These changes begin, and are more severe, distally but also affect more proximal segments of peripheral nerve, with the traumatic axotomy initiating the cellular changes in a distal-to-proximal fashion [51]. In order to evaluate the gross and histologic changes that occur to the entire nerve stump after nerve transection, we used the rabbit forelimb amputation model previously developed in our laboratory to analyze serial nerve sections obtained in a distal-toproximal fashion from the distal neuroma to the level of the brachial plexus-a clinical scenario often seen in targeted reinnervation patients.

In this study, significant increases in nerve cross-sectional area and myelinated axon count between treatment and control limbs were demonstrated at the distal nerve ends, consistent with previous studies [35]. Given what is known about neuroma histology, the increased nerve cross-sectional areas of the distal nerve endings in our study are mostly due to increased amounts of connective tissue stroma and inflammation in response to injury [5]. The increased myelinated axon counts in the distal nerve sections seen in our study can be explained by the fact that after peripheral nerve transection, a single parent axon produces numerous daughter sprouts [52-54]. As demonstrated in Table 1, the total myelinated axon area accounts for $25-32 \%$ of the total nerve cross-sectional area for both the treatment nerves 15 mm proximally and the control nerves. However, this ratio progressively decreases to only $5-11 \%$ of total nerve area when moving distally down the nerve, even though the number of myelinated axon fibers increases. Although the differences in total axon area and nerve cross-sectional area seen distally are partly due to increased connective tissue and inflammation, there is also less myelinated tissue distally, which may be due to axon demyelination, and thus the true count of axon sprouts-myelinated and unmyelinated-would be even higher than measured in this study. Additionally, the cross-sectional area of myelinated axons was significantly decreased in all serial sections of the treatment nerves, indicating that, without a distal target for these sprouts to grow into, axonal atrophy continued to proceed in a distal-to-proximal fashion to the level of the brachial plexus. However, increases in nerve cross-sectional area and myelinated axon count diminished distally-to-proximally with values normalizing by $15 \mathrm{~mm}$ proximal to the amputation. With time and increased axon loss, the amputated nerves may reduce in size even further. For example, the cross-sectional area of the median nerve at the point $15 \mathrm{~mm}$ proximally was significantly decreased compared to that of the control nerve.

In a rabbit peroneal nerve injury model, Gutmann and Sanders demonstrated that myelinated fiber sizes were significantly smaller $15 \mathrm{~mm}$ proximal to the lesion compared to controls up to 130 days after injury, with only slightly increased myelinated fiber numbers [41]. Our findings are more consistent with those of Aitken, who demonstrated that in the nerve to the gastrocnemius muscle of the rabbit, the number of myelinated fibers proximal to a neuroma increased by greater than $50 \%$ after nerve transection, with an elevated number of small myelinated fibers [55]. However, although Aitken noted that the marked increase in myelinated fibers 
Table 1 Measurements of Total Axon Area and Nerve Area

\begin{tabular}{|c|c|c|c|c|c|}
\hline Nerve & $\begin{array}{c}\text { Nerve cross-sectional } \\
\text { area }\left(\mu \mathrm{m}^{2}\right) \\
(\text { Normalized) }\end{array}$ & $\begin{array}{c}\text { Myelinated axon } \\
\text { count } \\
\text { (Normalized) }\end{array}$ & $\begin{array}{l}\text { Myelinated axon cross- } \\
\text { sectional area }\left(\mu \mathrm{m}^{2}\right) \\
\text { (Normalized) }\end{array}$ & $\begin{array}{l}\text { Total myelinated } \\
\text { axon area }\left(\mu \mathrm{m}^{2}\right)^{*}\end{array}$ & $\begin{array}{c}\text { Total myelinated axon } \\
\text { area/Nerve cross-sectional } \\
\text { area }\end{array}$ \\
\hline \multicolumn{6}{|l|}{ Median } \\
\hline Distal end & $823100(1.71)$ & $9349(2.44)$ & $8.0(0.25)$ & 74325 & 0.090 \\
\hline $\begin{array}{l}5 \mathrm{~mm} \\
\text { proximally }\end{array}$ & $651600(1.36)$ & $7434(1.94)$ & $14.7(0.47)$ & 109205 & 0.168 \\
\hline $\begin{array}{l}10 \mathrm{~mm} \\
\text { proximally }\end{array}$ & $421600(0.88)$ & $5449(1.42)$ & $16.1(0.51)$ & 87729 & 0.208 \\
\hline $\begin{array}{l}15 \mathrm{~mm} \\
\text { proximally }\end{array}$ & $326000(0.68)$ & $3463(0.90)$ & $27.7(0.88)$ & 95925 & 0.294 \\
\hline Control & $480300(1.00)$ & $3839(1.00)$ & $31.5(1.00)$ & 120967 & 0.252 \\
\hline \multicolumn{6}{|l|}{ Radial } \\
\hline Distal end & 2498000 (3.19) & $13280(2.42)$ & $9.2(0.24)$ & 121817 & 0.049 \\
\hline $\begin{array}{l}5 \mathrm{~mm} \\
\text { proximally }\end{array}$ & $1327000(1.70)$ & $9346(1.70)$ & $16.4(0.43)$ & 153461 & 0.116 \\
\hline $\begin{array}{l}10 \mathrm{~mm} \\
\text { proximally }\end{array}$ & $825100(1.05)$ & $7445(1.36)$ & $21.5(0.57)$ & 160216 & 0.194 \\
\hline $\begin{array}{l}15 \mathrm{~mm} \\
\text { proximally }\end{array}$ & $708100(0.91)$ & $6525(1.19)$ & $29.3(0.77)$ & 191052 & 0.270 \\
\hline Control & $782300(1.00)$ & $5494(1.00)$ & $37.9(1.00)$ & 207948 & 0.266 \\
\hline \multicolumn{6}{|l|}{ Ulnar } \\
\hline Distal end & $608500(2.49)$ & 8407 (2.76) & $8.1(0.32)$ & 68391 & 0.112 \\
\hline $\begin{array}{l}5 \mathrm{~mm} \\
\text { proximally }\end{array}$ & $327400(1.34)$ & $5370(1.76)$ & $10.7(0.42)$ & 57459 & 0.176 \\
\hline $\begin{array}{l}10 \mathrm{~mm} \\
\text { proximally }\end{array}$ & $240500(0.98)$ & $3308(1.08)$ & $15.2(0.60)$ & 50381 & 0.209 \\
\hline $\begin{array}{l}15 \mathrm{~mm} \\
\text { proximally }\end{array}$ & $204600(0.84)$ & $2701(0.89)$ & $23.4(0.93)$ & 63122 & 0.309 \\
\hline Control & $244500(1.00)$ & $3050(1.00)$ & $25.2(1.00)$ & 76952 & 0.315 \\
\hline
\end{tabular}

*Total myelinated axon area $=$ Myelinated axon count $\times$ Myelinated axon cross-sectional area

occurred immediately proximal to neuromas, how far proximally the regenerating fibers grew in a retrograde fashion was not evaluated. Using a mouse sural nerve model, Scadding and Thomas demonstrated a 37\% increase in myelinated axons at a distance of $1.5 \mathrm{~cm}$ proximal to the point of nerve section after 10 weeks [56]. In our study, the increased number of myelinated axons in the amputated nerves progressively normalized compared to controls in a distal-to-proximal fashion; therefore, there were no significant differences in the median, radial, and ulnar neuromas in terms of myelinated axon counts at a distance of $15 \mathrm{~mm}$ proximally. However, it is important to note that whereas Scadding and Thomas used a mouse sural (purely sensory) nerve model, our study employed larger caliber mixed (motor and sensory) nerves in the rabbit, making comparisons difficult to draw. In addition, unlike the methodology of Scadding and Thomas, the distal $5 \mathrm{~mm}$ of neuroma was excised and excluded for each nerve in our study in an effort to replicate what is done in targeted reinnervation procedures, thereby making the " $15 \mathrm{~mm}$ proximal" group in our study, in reality, $20 \mathrm{~mm}$ from the distal end of the neuroma.
The extent of retrograde degeneration of amputated nerves has both functional and therapeutic implications since aberrant discharges are spontaneously generated by both neuromas and retrograde axon sprouts [54,57-61]. In a rat sciatic nerve model, Wall and Gutnick demonstrated that smaller fibers within neuromas produce ongoing spontaneous activity that may be responsible for sensations of pain [61]. In a study assessing neuromas of the superficial radial nerve in baboons, Meyer et al. found that spontaneously active fibers were present in the neuromas, consisting of both myelinated and unmyelinated axons that were mechanically sensitive, with apparent crosstalk between fibers within the neuroma [7]. Sixty-seven percent of the spontaneously active fibers in the neuroma were unmyelinated, compared to $19 \%$ in the control, pointing out a potential link between neuromas and nociceptive pathways. Amir and Devor showed in a rat sciatic neuroma model that spontaneous discharges occurred in afferents that terminated in the neuroma, as well as in afferents that had emitted retrograde sprouts [57]. In fact $39 \%$ of fibers with retrograde sprouting carried spontaneous ongoing discharges, and, conversely, the authors point out those 
axons with spontaneous activity were significantly more likely to have a retrograde sprout. Amir and Devor proposed that individual neurons that emit retrograde sprouts have an unusually high likelihood of firing spontaneously [57], which, in conjunction with an increased capacity for myelinated A- $\beta$ sprouts to make contact with nociceptive-specific neurons [62-64], can result in pain.

Repeated noxious stimuli-as in the case of an acutely injured peripheral nerve, in addition to spontaneous discharges from neuromas and sprouting axons-lead to decreased activation thresholds, and responses to subsequent stimuli are thereby amplified $[65,66]$. The aforementioned increase in excitability further exacerbates nociception by leading to decreased inhibition from afferent fibers [67-69], thereby creating a state of central sensitization of neural tissue involved in pain perception. Whereas potential therapies for central pain pathways are beyond the scope of this discussion [70-72], the noxious stimuli in the peripheral nervous system that ignite the cycle of events that ultimately lead to central perceptions of pain are important for this discussion. With retrograde sprouts being able-and more likely-to produce spontaneous, ectopic discharges after peripheral nerve injury, it is possible that neuroma treatment procedures should focus not only on excising the neuromas, but also on removing any proximal neural tissue that contains retrograde axonal sprouts.

During clinical procedures for the treatment of symptomatic neuromas, in addition to nerve transfer procedures like targeted reinnervation, complete excision of the "neuroma" is recommended, but where exactly does the neuroma begin? In our study, gross neuroma appearance did not correlate with the "zone of injury" of the proximal nerve stump on an axonal level. Morphologic changes at the axonal level extended beyond the region of gross neuroma formation, measured as nerve cross-sectional area, in a distal-to-proximal fashion after nerve transection, supporting the first of two main intra-operative concepts: First, a normal-sized nerve end does not necessarily mean that the nerve is internally normal. Second, approximately 2 centimeters proximal to a neuroma bulb, in a rabbit, the majority of sprouted axons would be removed. Given the potential for retrograde axon sprouts to produce ectopic, spontaneous, and painful discharges, we propose that cutting back more proximally on the nerve stump, beyond the appearance of grossly normal-appearing fascicles, may be beneficial during neuroma surgery in symptomatic patients. Employing the use of intra-operative frozen sections would be an effective method of minimizing, if not eliminating, any neural tissue that contains retrograde sprouts. However, this raises the interesting question of whether there is an optimal site to cut back on a neuroma that is going to be used for nerve transfer, such as targeted reinnervation. Cutting back further proximally will leave a nerve segment with fewer axon sprouts than using a nerve segment that is closer to the neuroma bulb, though it has yet to be determined whether cutting back in this fashion would have any detrimental functional consequences. Also, there are clinical scenarios for which nerve length is a major limiting factor where it would be unfeasibledetrimental even-to cut back neuromas more proximally, such as when treating neuromas-in-continuity for brachial plexus reconstruction. Injuries to the brachial plexus itself can potentially demonstrate histologic changes proximally to the level of the cervical root or spinal cord, making excision and subsequent reconstruction impractical. On the other hand, when performing targeted reinnervation, the nerves can be cut far proximally $(3-12 \mathrm{~cm})$ from the end-neuroma without difficulty or consequence. Therefore, the surgeon must decide how far proximally to cut back on a neuroma based on the clinical indication and overall operative plan.

When considering the discrepancy that exists between gross and histologic neuromas, one must change how we evaluate neuromas, not only clinically, but also with respect to bench research. There is a need for improved standardization among neuroma models in terms of where along the length of the proximal nerve stump measurements should be made. A look at several largeanimal neuroma models makes it apparent that little mention is made as to where exactly, whether in the neuroma itself or at a specified distance proximal to the gross neuroma, histologic analysis is being performed $[6,73,74]$. A neuroma at its largest diameter has different characteristics than a nerve segment just $5 \mathrm{~mm}$ proximally, as reinforced by our study. It is imperative that data collection in animal models that relies on axon counts, axon size, and other quantitative parameters must therefore standardize the sites where nerve measurements are made.

\section{Conclusions}

Using a rabbit forelimb amputation model that was developed to further assess targeted reinnervation, we determined that morphologic changes at the axonal level extend beyond the region of gross neuroma formation in a distal-to-proximal fashion after nerve transection at the level of the brachial plexus. Normal-sized nerves do not correlate with normal nerve histomorphometry in this model, and the discrepancy between gross and histologic neuromas indicates potential implications for how neuromas should be viewed, both in the laboratory and in the operating room. 


\section{Acknowledgements and Funding}

The authors would like to extend a special thanks to Dr. Diana Berger, Dr. Charlette Cain, and the rest of the veterinary staff at the Center for Comparative Medicine at Northwestern University for their assistance with animal care from the inception of the amputation model and throughout the course of this study. The authors would also like to thank Linda Juarez at the University of Illinois at Chicago Research Resources Center for her nerve histology technical support and expertise. This study was funded, in part, by the 2008 Plastic Surgery Educational Foundation (PSEF) Fellowship grant awarded to Dr. Jason Ko.

\section{Author details}

'Department of Surgery, Division of Plastic and Reconstructive Surgery, Northwestern University, Feinberg School of Medicine, Chicago, IL, USA. ${ }^{2}$ Department of Pathology, Northwestern University, Feinberg School of Medicine, Chicago, IL, USA. ${ }^{3}$ Neural Engineering Center for Artificial Limbs (NECAL), Rehabilitation Institute of Chicago, Chicago, IL, USA.

\section{Authors' contributions}

JK participated in design and execution of the model, histomorphometric analysis, and drafting of the manuscript. PK participated in preparation of the manuscript; $\mathrm{KO}$ engineered the imbedding and histomorphometric techniques specific for the needs of this model; XD performed critical macroscopic and microscopic analysis of the histologic specimens; and TK and GD participated in the design and coordination of the model. All authors read and approved the final manuscript.

\section{Competing interests}

The authors declare that they have no competing interests.

Received: 28 September 2010 Accepted: 13 October 2011

Published: 13 October 2011

\section{References}

1. Waller A: Experiments on the sections of glossopharyngeal and hypoglossal nerves of the frog and observations of the alterations produced thereby in the structure of their primitive fibers. Phil Trans $R$ Soc Lond 1850, 140:423-429.

2. Ramon y Cajal S: Mechanismo de la degeneration y regeneration de nervos. Trab Lab Inbest Biol 1905, 9:119.

3. Ann ES, Mizoguchi A, Okajima S, et al: Motor axon terminal regeneration as studied by protein gene product 9.5 immunohistochemistry in the rat. Arch Histol Cytol 1994, 57(4):317-330

4. Mackinnon SE: Neuromas. Foot Ankle Clin 1998, 3:385-404.

5. Cravioto $H$, Battista A: Clinical and ultrastructural study of painful neuroma. Neurosurgery 1981, 8(2):181-190.

6. Mackinnon SE, Dellon AL, Hudson AR, et al: Alteration of neuroma formation by manipulation of its microenvironment. Plast Reconstr Surg 1985, 76(3):345-353.

7. Meyer RA, Raja SN, Campbell JN, et al: Neural activity originating from a neuroma in the baboon. Brain Res 1985, 325(1-2):255-260.

8. Mass DP, Ciano MC, Tortosa R, et al: Treatment of painful hand neuromas by their transfer into bone. Plast Reconstr Surg 1984, 74(2):182-185.

9. Iadarola MJ, Max MB, Berman KF, et al: Unilateral decrease in thalamic activity observed with positron emission tomography in patients with chronic neuropathic pain. Pain 1995, 63(1):55-64.

10. Battista AF, Cravioto HM, Budzilovich GN: Painful neuroma: changes produced in peripheral nerve after fascicle ligation. Neurosurgery 1981, 9(5):589-600.

11. Gonzalez-Darder J, Barbera J, Alamo J, et al: Fascicular ligation in the prevention and treatment of painful terminal neuroma: an experimental study in the rat. Neurosurgery 1987, 21(2):215-217.

12. Muehleman C, Rahimi F: Effectiveness of an epineurial barrier in reducing axonal regeneration and neuroma formation in the rat. J Foot Surg 1990, 29(3):260-264

13. Robbins TH: Nerve capping in the treatment of troublesome terminal neuromata. Br J Plast Surg 1986, 39(2):239-240.

14. Sakai $Y$, Ochi M, Uchio $Y$, et al: Prevention and treatment of amputation neuroma by an atelocollagen tube in rat sciatic nerves. $J$ Biomed Mater Res B Appl Biomater 2005, 73(2):355-360.
15. Swanson $A B$, Boeve NR, Lumsden RM: The prevention and treatment of amputation neuromata by silicone capping. J Hand Surg Am 1977, 2(1):70-78.

16. Gonzalez-Darder J, Barbera J, Abellan MJ, et al: Centrocentral anastomosis in the prevention and treatment of painful terminal neuroma. An experimental study in the rat. J Neurosurg 1985, 63(5):754-758,

17. Ashley L, Stallings JO: End-to-side nerve flap for treatment of painfu neuroma: a 15-year follow-up. J Am Osteopath Assoc 1988, 88(5):621-624.

18. Barbera J, bert-Pamplo R: Centrocentral anastomosis of the proximal nerve stump in the treatment of painful amputation neuromas of major nerves. J Neurosurg 1993, 79(3):331-334

19. Boldney E: Amputation neuromas in nerves implanted into bone. Ann Surg 2009, 118:1052-1057.

20. Tupper JW, Booth DM: Treatment of painful neuromas of sensory nerves in the hand: a comparison of traditional and newer methods. J Hand Surg Am 1976, 1(2):144-151.

21. Burchiel KJ, Johans TJ, Ochoa J: The surgical treatment of painful traumatic neuromas. J Neurosurg 1993, 78(5):714-719.

22. Dellon AL, Mackinnon SE, Pestronk A: Implantation of sensory nerve into muscle: preliminary clinical and experimental observations on neuroma formation. Ann Plast Surg 1984, 12(1):30-40

23. Dellon AL, Mackinnon SE: Treatment of the painful neuroma by neuroma resection and muscle implantation. Plast Reconstr Surg 1986, 77(3):427-438

24. Herndon JH, Eaton RG, Littler JW: Management of painful neuromas in the hand. J Bone Joint Surg Am 1976, 58(3):369-373.

25. Balcin $H$, Erba $P$, Wettstein $R$, et al: A comparative study of two methods of surgical treatment for painful neuroma. J Bone Joint Surg Br 2009, 91(6):803-808.

26. Herbert TJ, Filan SL: Vein implantation for treatment of painful cutaneous neuromas. A preliminary report. J Hand Surg Br 1998, 23(2):220-224.

27. Mobbs RJ, Vonau M, Blum P: Treatment of painful peripheral neuroma by vein implantation. J Clin Neurosci 2003, 10(3):338-339.

28. Kakinoki R, lkeguchi R, Matsumoto $\mathrm{T}$, et al: Treatment of painful peripheral neuromas by vein implantation. Int Orthop 2003, 27(1):60-64.

29. Kuiken TA, Dumanian GA, Lipschutz RD, et al: The use of targeted muscle reinnervation for improved myoelectric prosthesis control in a bilateral shoulder disarticulation amputee. Prosthet Orthot Int 2004, 28(3):245-253.

30. Hijjawi JB, Kuiken TA, Lipschutz RD, et al: Improved myoelectric prosthesis control accomplished using multiple nerve transfers. Plast Reconstr Surg 2006, 118(7):1573-1578

31. Kuiken TA, Miller LA, Lipschutz RD, et al: Targeted reinnervation for enhanced prosthetic arm function in a woman with a proximal amputation: a case study. Lancet 2007, 369(9559):371-380

32. O'Shaughnessy KD, Dumanian GA, Lipschutz RD, et al: Targeted reinnervation to improve prosthesis control in transhumeral amputees. A report of three cases. J Bone Joint Surg Am 2008, 90(2):393-400.

33. Dumanian GA, Ko JH, O'Shaughnessy KD, et al: Targeted reinnervation for transhumeral amputees: current surgical technique and update on results. Plast Reconstr Surg 2009, 124(3):863-869.

34. Kuiken TA, Li G, Lock BA, et al: Targeted muscle reinnervation for realtime myoelectric control of multifunction artificial arms. JAMA 2009, 301(6):619-628.

35. Kim PS, Ko J, O'Shaughnessy KK, et al: Novel model for end-neuroma formation in the amputated rabbit forelimb. I Brachial Plex Peripher Nerve Inj 2010, 5:6.

36. CRAGG BG, THOMAS PK: Changes in conduction velocity and fibre size proximal to peripheral nerve lesions. J Physiol 1961, 157:315-327.

37. Dyck PJ, Lais A, Karnes J, et al: Peripheral axotomy induces neurofilament decrease, atrophy, demyelination and degeneration of root and fasciculus gracilis fibers. Brain Res 1985, 340(1):19-36.

38. Dyck PJ, Lais AC, Karnes $\mathrm{JL}$, et al: Permanent axotomy, a model of axonal atrophy and secondary segmental demyelination and remyelination. Ann Neurol 1981, 9(6):575-583.

39. Gillespie MJ, Stein RB: The relationship between axon diameter, myelin thickness and conduction velocity during atrophy of mammalian peripheral nerves. Brain Res 1983, 259(1):41-56.

40. Gordon T, Gillespie J, Orozco R, et al: Axotomy-induced changes in rabbit hindlimb nerves and the effects of chronic electrical stimulation. J Neurosci 1991, 11(7):2157-2169. 
41. Gutmann E, Sanders FK: Recovery of fibre numbers and diameters in the regeneration of peripheral nerves. J Physiol 1943, 101(4):489-518.

42. Kreutzberg GW, Schubert P: Volume changes in the axon during regeneration. Acta Neuropathol 1971, 17(3):220-226.

43. Hunter DA, Moradzadeh A, Whitlock EL, et al: Binary imaging analysis for comprehensive quantitative histomorphometry of peripheral nerve. $J$ Neurosci Methods 2007, 166(1):116-124.

44. da Silva AP, Jordao CE, Fazan VP: Peripheral nerve morphometry: Comparison between manual and semi-automated methods in the analysis of a small nerve. J Neurosci Methods 2007, 159(1):153-157.

45. Lieberman AR: The axon reaction: a review of the principal features of perikaryal responses to axon injury. Int Rev Neurobiol 1971, 14:49-124.

46. Torvik A: Central chromatolysis and the axon reaction: a reappraisal. Neuropathol Appl Neurobiol 1976, 2:423-432.

47. Ranson SW: Retrograde degeneration in the spinal nerves. J Comp Neurol 1906, 16:265-293.

48. Sunderland S: Nerve and nerve injuries London: Churchill Livingstone; 1972.

49. Fu SY, Gordon T: The cellular and molecular basis of peripheral nerve regeneration. Mol Neurobiol 1997, 14(1-2):67-116.

50. Kuno M: Target dependence of motoneuronal survival: the current status. Neurosci Res 1990, 9(3):155-172.

51. Dyck PJ, Nukada H, Lais AC, et al: Permanent axotomy: a model of chronic neuronal degeneration preceded by axonal atrophy, myelin remodeling, and degeneration. In Peripheral Neuropathy. Edited by: Dyck PJ, THOMAS PK, Lambert EH, et al. Philadelphia: W.B. Saunders; 1984:760-870

52. Ma J, Novikov LN, Wiberg M, et al: Delayed loss of spinal motoneurons after peripheral nerve injury in adult rats: a quantitative morphological study. Exp Brain Res 2001, 139(2):216-223.

53. Aitken JT, Sharman M, Young JZ: Maturation of regenerating nerve fibres with various peripheral connexions. J Anat 1947, 81(Pt 1):1-22.

54. Scadding JW: Development of ongoing activity, mechanosensitivity, and adrenaline sensitivity in severed peripheral nerve axons. Exp Neurol 1981, 73(2):345-364.

55. Aitken JT: The effect of peripheral connexions on the maturation of regenerating nerve fibres. J Anat 1949, 83(Pt. 1):32-43.

56. Scadding JW, THOMAS PK: Retrograde growth of myelinated fibres in experimental neuromas. J Anat 1983, 136(Pt 4):793-799.

57. Amir R, Devor M: Ongoing activity in neuroma afferents bearing retrograde sprouts. Brain Res 1993, 630(1-2):283-288.

58. Burchiel KJ: Effects of electrical and mechanical stimulation on two foci of spontaneous activity which develop in primary afferent neurons after peripheral axotomy. Pain 1984, 18(3):249-265.

59. Govrin-Lippmann R, Devor M: Ongoing activity in severed nerves: source and variation with time. Brain Res 1978, 159(2):406-410.

60. Wall PD, Devor M: Sensory afferent impulses originate from dorsal root ganglia as well as from the periphery in normal and nerve injured rats. Pain 1983, 17(4):321-339.

61. Wall PD, Gutnick M: Ongoing activity in peripheral nerves: the physiology and pharmacology of impulses originating from a neuroma. Exp Neurol 1974, 43(3):580-593.

62. Woolf $\mathrm{CJ}$, Shortland $\mathrm{P}$, Coggeshall RE: Peripheral nerve injury triggers central sprouting of myelinated afferents. Nature 1992, 355(6355):75-78.

63. Woolf CJ, Shortland P, Reynolds M, et al: Reorganization of central terminals of myelinated primary afferents in the rat dorsal horn following peripheral axotomy. J Comp Neurol 1995, 360(1):121-134.

64. Mannion RJ, Doubell TP, Coggeshall RE, et al: Collateral sprouting of uninjured primary afferent A-fibers into the superficial dorsal horn of the adult rat spinal cord after topical capsaicin treatment to the sciatic nerve. J Neurosci 1996, 16(16):5189-5195.

65. Woolf CJ, Salter MW: Neuronal plasticity: increasing the gain in pain. Science 2000, 288(5472):1765-1769.

66. Ji RR, Kohno T, Moore KA, et al: Central sensitization and LTP: do pain and memory share similar mechanisms? Trends Neurosci 2003, 26(12):696-705.

67. Yaksh TL: Behavioral and autonomic correlates of the tactile evoked allodynia produced by spinal glycine inhibition: effects of modulatory receptor systems and excitatory amino acid antagonists. Pain 1989, 37(1):111-123.

68. Sivilotti L, Woolf CJ: The contribution of GABAA and glycine receptors to central sensitization: disinhibition and touch-evoked allodynia in the spinal cord. J Neurophysiol 1994, 72(1):169-179.
69. Torsney C, MacDermott AB: Disinhibition opens the gate to pathological pain signaling in superficial neurokinin 1 receptor-expressing neurons in rat spinal cord. J Neurosci 2006, 26(6):1833-1843.

70. Ramachandran VS, Rogers-Ramachandran D: Synaesthesia in phantom limbs induced with mirrors. Proc Biol Sci 1996, 263(1369):377-386.

71. Chan BL, Witt R, Charrow AP, et al: Mirror therapy for phantom limb pain. N Engl J Med 2007, 357(21):2206-2207.

72. Ramachandran VS, Rogers-Ramachandran D: Sensations referred to a patient's phantom arm from another subjects intact arm: perceptual correlates of mirror neurons. Med Hypotheses 2008, 70(6):1233-1234.

73. Song C, Zhang F, Zhang J, et al: Neuroma-in-continuity model in rabbits. Ann Plast Surg 2006, 57(3):317-322.

74. Elwakil TF, Elkharbotly A: Role of Nd:YAG laser for prevention of neuroma formation: an in vivo experimental study. Lasers Med Sci 2008, 23(2):163-168

\section{doi:10.1186/1749-7221-6-8}

Cite this article as: Ko et al:: A quantitative evaluation of gross versus histologic neuroma formation in a rabbit forelimb amputation model: potential implications for the operative treatment and study of neuromas. Journal of Brachial Plexus and Peripheral Nerve Injury 2011 6:8.

\section{Submit your next manuscript to BioMed Central and take full advantage of:}

- Convenient online submission

- Thorough peer review

- No space constraints or color figure charges

- Immediate publication on acceptance

- Inclusion in PubMed, CAS, Scopus and Google Scholar

- Research which is freely available for redistribution

Submit your manuscript at www.biomedcentral.com/submit
C Biomed Central 